\title{
AP-2 $\alpha$ Inhibits c-MYC Induced Oxidative Stress and Apoptosis in HaCaT Human Keratinocytes
}

\author{
Lei Yu, ${ }^{1}$ Michael J. Hitchler, ${ }^{1}$ Wenqing Sun, ${ }^{1}$ Ehab H. Sarsour, ${ }^{1}$ Prabhat C. Goswami, ${ }^{1}$ \\ Aloysius J. Klingelhutz, ${ }^{2}$ and Frederick E. Domann ${ }^{1}$
}

\author{
${ }^{1}$ Free Radical \& Radiation Biology Graduate Program, Radiation Oncology Department, Roy J. and \\ Lucille A. Carver College of Medicine, The University of Iowa, Iowa City, IA 52242, USA \\ ${ }^{2}$ Department of Microbiology, Roy J. and Lucille A. Carver College of Medicine, The University of Iowa, \\ Iowa City, IA 52242, USA
}

Correspondence should be addressed to Frederick E. Domann, frederick-domann@uiowa.edu

Received 11 June 2009; Accepted 2 October 2009

Recommended by Jörg Kleeff

\begin{abstract}
AP- $2 \alpha$ and c-MYC are important transcription factors involved in multiple cellular processes. They each display the paradoxical capacities to stimulate both cell proliferation and apoptosis under different conditions. In the present study we found that over expression of c-MYC was associated with accumulation of reactive oxygen species (ROS) and apoptosis in human keratinocytes, both of which were significantly inhibited by co-expression of AP-2. The effects of AP-2 on c-MYC were active at several levels. First, AP-2 and c-MYC were confirmed to interact at the protein level as previously described. In addition, forced expression of AP-2 significantly decreased steady state levels of c-MYC mRNA and protein. These findings suggested that AP-2 may have a direct effect on the $c-m y c$ gene. Chromatin immunoprecipitation assays demonstrated that AP-2 proteins bound to a cluster of AP-2 binding sites located within a $2 \mathrm{~kb}$ upstream regulatory region of $c-m y c$ These results suggest that the negative regulation of AP-2 on c-MYC activity was achieved through binding of AP-2 protein to the $c-m y c$ gene. The effects of AP- 2 on c-MYC induced ROS accumulation and apoptosis in epidermal keratinocytes are likely to play an important role in cell growth, differentiation and carcinogenesis of the skin.
\end{abstract}

Copyright (C) 2009 Lei Yu et al. This is an open access article distributed under the Creative Commons Attribution License, which permits unrestricted use, distribution, and reproduction in any medium, provided the original work is properly cited.

\section{Introduction}

The c-MYC protein, which is encoded by $c$-myc gene, is a nuclear phosphoprotein. This protein belongs to the helixloop-helix/leucine zipper (HLH/LZ) family of transcription factors (including c-MYC, N-MYC, L-MYC, S- and B$\mathrm{MYC})$ and recognizes E-box sequences that contain a central CAC(G/A)TG sequence [1]. Although its precise cellular functions remain enigmatic, it is clear that c-MYC plays a critical role at some level in cell proliferation and differentiation [2]. For example, induction of c-MYC is sufficient to drive quiescent cells into the cell cycle, while inhibition of c-MYC can block mitogenic signals and facilitate cell differentiation [3]. A well-known human disease involving c-MYC is human Burkitt's lymphoma [4], in which $c-m y c$ is translocated from chromosome 8 to one of three chromosomes that contain antibody-encoding genes where its transcription is activated by those strong lymphocyte specific promoters. Gene amplification is another mechanism that leads to overexpression of c-MYC [5]. More recently, the overexpression and deregulation of $c-m y c$ in many of other types of tumors have been demonstrated [6]. Unlike other proto-oncogene products, c-MYC levels in different tumor types range from lower than their normal cells of origin to dramatically increased [7]. So deregulation, not simply amplification, is generally considered as the key point of carcinogenesis caused by c-MYC. Besides promoting cell proliferation, c-MYC also shows the capacity to induce cell death $[8,9]$. At high levels of expression, c-MYC cannot only sensitize cells to cell death, but also affect neighboring cells $[10,11]$. The apoptosis induced by c-MYC has been shown to depend on signaling via FasL/Fas pathway in T cells [12], increased cellular free radical levels [13], and can be either p53 dependent or p53 independent [14]. 
The exact mechanisms through which c-MYC mediates its diverse effects on cell fate are unknown. One possibility is that c-MYC functions as a classical transcription factor in the formation of heterodimers with Max or Mad and binds to E box related elements [15]. Another is the interaction of c-MYC with other proteins which have been predominantly mapped to occur through its C-terminal region (CTR) and $\mathrm{N}$-terminal region (NTR). Among the proteins identified in a direct interaction with c-MYC, transcription factor AP- $2 \alpha$ (TFAP2A) $[2,16]$ has been shown to have a similar pattern of biological behavior as c-MYC.

AP-2 is a transcription factor family that includes five members: AP- $2 \alpha, \mathrm{AP}-2 \beta, \mathrm{AP}-2 \gamma, \mathrm{AP}-2 \delta$, and the recently identified AP- $2 \varepsilon$. All AP- 2 family members share a common protein structure that includes a DNA binding domain, a dimerization domain, and a transactivating domain [17]. These transcription factors regulate the expression of genes involved in a wide spectrum of important biological functions, including cell proliferation, differentiation and carcinogenesis. AP- $2 \alpha$ has previously been shown to interact with the BR/HLH/LZ domain of c-MYC through C-terminal domains (amino acids 204-437) of AP- $2 \alpha$ and block the DNA binding of c-MYC [16]. Similar to c-MYC, the function of AP- $2 \alpha$ also has been found to be paradoxical. Some investigators found that AP- $2 \alpha$ was a tumor suppressor [18, 19 ] which had the capacity to induce apoptosis, while others suggested that AP- $2 \alpha$ could be a proto-oncogene $[20,21]$ which stimulated cell proliferation.

Although it has been shown that AP- $2 \alpha$ has a negative effect on c-MYC transcriptional activity in two bona fide target genes, prothymosin-alpha and ornithine decarboxylase [16], it is not clear whether AP- $2 \alpha$ has the capability to inhibit c-MYC induced transformation or apoptosis. Besides the known protein-protein interaction, whether there are other levels of interaction or regulation between these two transcription factors remains unknown.

Both AP-2 $\alpha$ [22] and c-MYC [23] can be induced by UVA irradiation. Furthermore, of $\mathrm{HaCaT}$ cells exposed to chronic UVA irradiation showed increased resistance to further UVA induced apoptosis [24]. Although this study did not measure the AP- $2 \alpha$ levels in those treated $\mathrm{HaCaT}$ cells, expression of the AP-2 target gene MMP9 was found to be significantly higher. We found in our own study that overexpression of AP- $2 \alpha$ in $\mathrm{HaCaT}$ cells before UVA irradiation could significantly increase cell survival (Supplemental Figure 1). These data strongly suggested that increased AP- $2 \alpha$ levels may protect cells from further UVA induced cell death, and inhibition of UVA-induced c-MYC expression could be one of the mechanisms behind the protection.

To better understand the biological effects of the interaction between c-MYC and AP- $2 \alpha$, we first overexpressed $\mathrm{c}-\mathrm{MYC}$ and monitored the generation of reactive oxygen species (ROS) and cell biology parameters including clonogenic survival and growth rates; then we co-overexpressed $\mathrm{AP}-2 \alpha$ to test the hypothesis that $\mathrm{AP}-2 \alpha$ can block at least some consequences of c-MYC overexpression in $\mathrm{HaCaT}$ human keratinocytes. AP-2dn, a transactivating domain truncated protein [20], was also overexpressed in $\mathrm{HaCaT}$

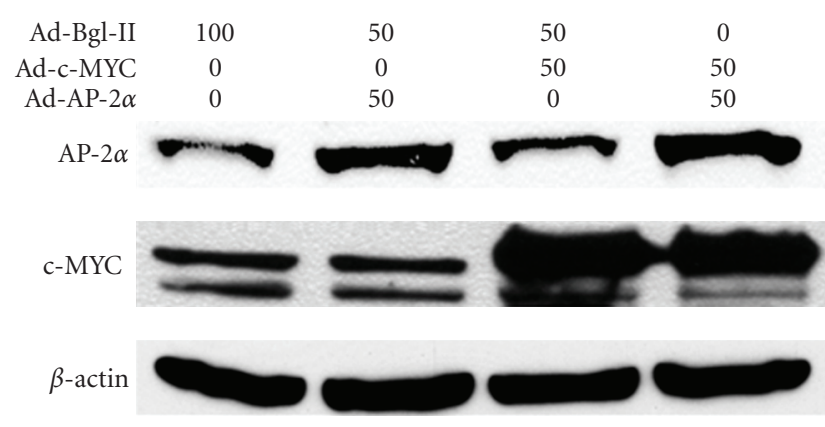

Figure 1: Adenovirus forced overexpression of AP-2 and c-MYC in $\mathrm{HaCaT}$ cells. HaCaT cells were infected with Ad-Bgl II $100 \mathrm{MOI}$ (control), 50 MOI Ad-Bgl II + 50 MOI Ad-AP-2 (AP-2 $\alpha$ ), 50 MOI Ad-Bgl II +50 MOI Ad-c-MYC (c-MYC), and 50 MOI Ad-AP$2+50$ MOI Ad-c-MYC (AP- $2 \alpha+c-M Y C)$. On the c-MYC blot (middle) the immunoreactivity that corresponds to the forced overexpression of the c-MYC is shown by the upper band. The figure is a representative of at least three independent blots.

cells to test whether the transcriptional activity of AP-2 was necessary for any effects on c-MYC activity.

\section{Results}

2.1. Overexpression of $c-M Y C$ Increased Intercellular ROS Levels. Overexpression of c-MYC and AP- $2 \alpha$ proteins in $\mathrm{HaCaT}$ cells was confirmed by western blot (Figure 1). As early as 9 hours after infection with 50 MOI Ad-cMYC, the intercellular ROS level, as detected by DCF method, was significantly increased relative to controls (Figure 2(a)) and by 24 hours it reached to about a 30fold increase (Figure 2(b)). Overexpression of AP- $2 \alpha$ alone did not increase ROS level compared to control vector BglII. Thus, c-MYC overexpression was linked to a significant increase of ROS, while co-overexpression of AP- $2 \alpha$ with cMYC alleviated the increase of ROS (Figure 2(b)).

\subsection{AP-2 $\alpha$ Partially Prevented Cell Death Induced by Over-} expression c-MYC in $\mathrm{HaCaT}$ Cells. c-MYC overexpression caused a dramatic decrease of clonogenic cell survival, with surviving fractions decreasing to approximately $20 \%$ (Figure 3). Coexpression of AP- $2 \alpha$ significantly rescued the cells and increased the surviving fraction, doubling it to approximately $40 \%$. Forced AP- $2 \alpha$ overexpression alone did not have a detectable effect on clonogenic survival in $\mathrm{HaCaT}$ cells at a titer of $50 \mathrm{MOI}$. This is in contrast to results previously determined for human breast carcinoma cells [25] and may reflect the relatively higher endogenous level of AP$2 \alpha$ expression in human keratinocytes.

\subsection{AP-2 $\alpha$ Attenuated c-MYC Induced Apoptosis in HaCaT} Cells. Two independent assays for apoptosis, propidium iodide (PI) DNA staining and caspase-3 activation, showed that overexpression of c-MYC in $\mathrm{HaCaT}$ cells induced apoptosis (Figure 4). Fifty MOI of Ad-c-MYC increased the sub-G1 apoptotic population about 3 times compared to the control group $(P<.01)$ (Figure $4(a))$, while coexpression 


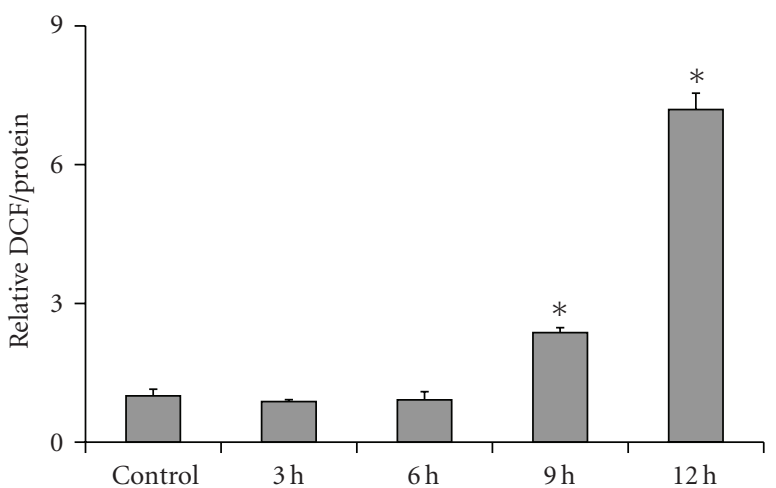

(a)

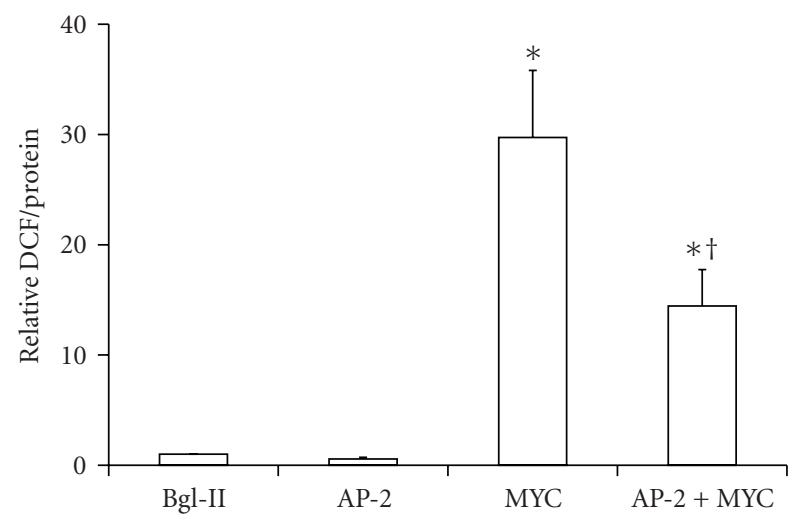

(b)

FIgURE 2: c-MYC induced accumulation of ROS in HaCaT cells was partially reversed by AP- $2 \alpha$. (a) time course showed that as early as 9 hours after infection, ROS level was higher than control $\left({ }^{*} P<\right.$ .05 versus control, $n=3$ ); (b) AP-2 reduced the ROS induced by cMYC. The intercellular ROS level was measured by DCF method 24 hours after infection. Overexpression of AP-2 alone did not increase ROS level while co-overexpression AP-2 with c-MYC significantly decreased the accumulation of ROS $\left({ }^{*} P<.05\right.$ versus Bg-II and AP- $2 ;{ }^{\dagger} P<.05$ versus MYC, $n=3$ ).

of AP- $2 \alpha$ relieved that increase back to the basal level. Although sub-G1 content DNA level by PI staining indicates death, it is not specific for apoptosis. Thus, the activated caspase-3 assay was employed as it is more specific to the detection of apoptosis in these cells (Figure 4(b)). cMYC increased the fraction of the active caspase- 3 positive population from $4.5 \%$ to $40 \%$ ( $\sim 10$ fold $)$, while coexpression of AP- $2 \alpha$ decreased this increase to around $15 \%$ ( $\sim 3$ fold $)$ (Figure 4(b)).

2.4. AP-2 $\alpha$ Inhibits the Expression of Endogenous c-myc. After we found that overexpression of AP- 2 could inhibit at least some of the consequences of exogenously expressed c-MYC, we further investigated whether AP-2 had similar effects on endogenous c-MYC. AP- $2 \alpha$ and c-MYC are both transcription factors; therefore, besides the direct protein interaction, it is possible that these two factors affect each others' gene expression. We found that overexpression of AP$2 \alpha$ decreased the steady-state levels of both c-MYC mRNA

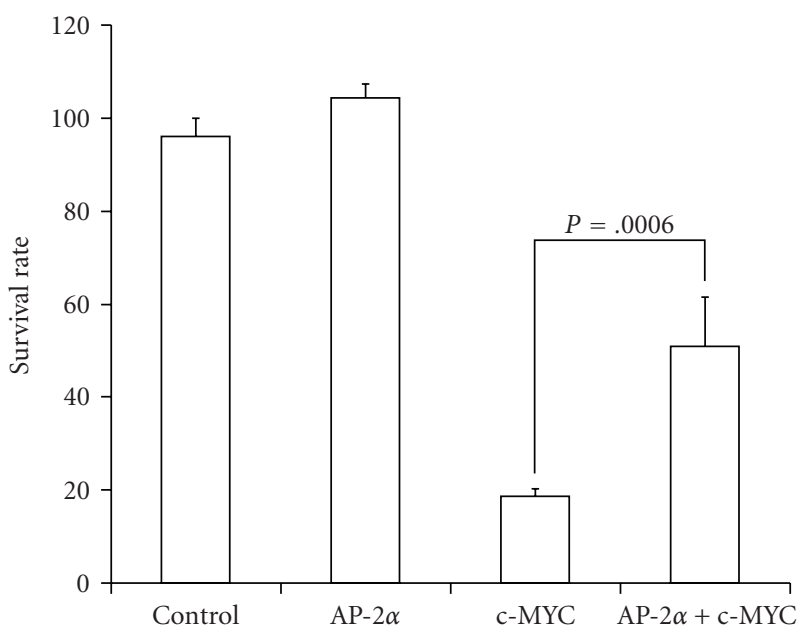

Figure 3: c-MYC induced cell death in HaCaT cells was partially reversed by AP- $2 \alpha$. Twenty-four hours after infection, 100 cells from each group were seeded and cultured under normal growth conditions for 10-14 days. Colonies with $\geq 50$ cells were counted. $\mathrm{AP}-2 \alpha$ increased clonogenic survival in c-MYC overexpressing $\mathrm{HaCaT}$ cells. The surviving fractions were calculated by normalizing the number of colony of each treated group to that of the control group, respectively. Error bars stand for standard deviations, $n=3$.

and protein compared to the vector control (Figures 5(a) and $5(\mathrm{~b})$ ). Interestingly, a transactivation domain deletion mutant of AP- $2 \alpha$ had a similar effect, suggesting that there is a blocking effect of AP-2 on the c-MYC promoter. Analysis of $2 \mathrm{~kb} 5^{\prime}$ flanking region of the $c$-myc gene revealed that there were 11 putative AP-2 binding sites located within that area and three more in the first intron (Figure 6(a)). To determine whether AP-2 is capable of direct DNA binding to these cis elements, we performed in vivo quantitative chromatin immunoprecipitate (qChIP) assays. The qChIP assays showed that overexpression of AP- $2 \alpha$ caused significant enrichment (approximately 6 folds) for both selected promoter regions analyzed compared to the vector control group (Figure 6(b)). Another genomic region that was previously known to contain an AP-2 binding site, the ICAM-1 promoter [22], was used as a positive control, and was enriched approximately 10 folds (data not shown). Since the interaction between these two proteins required the C-terminal end of both proteins [16] and blocked c-MYC DNA binding, we tested whether this interaction also blocked AP-2 DNA binding. We found, in vitro, that an increase of c-MYC protein amount caused a decrease of AP-2 DNA binding which was detected by gel shift assay (Supplementary Figure 2 in supplementary material available online at doi $10.1155 / 2003 / 780874)$ and, in vivo, cooverexpression of cMYC could decrease the binding of AP-2 to $c-m y c$ promoter (Figure 6(b)).

\section{Discussion}

The Myc family of nuclear oncoproteins, including c-MYC, N-MYC, and L-MYC are key cell growth regulators. Among 

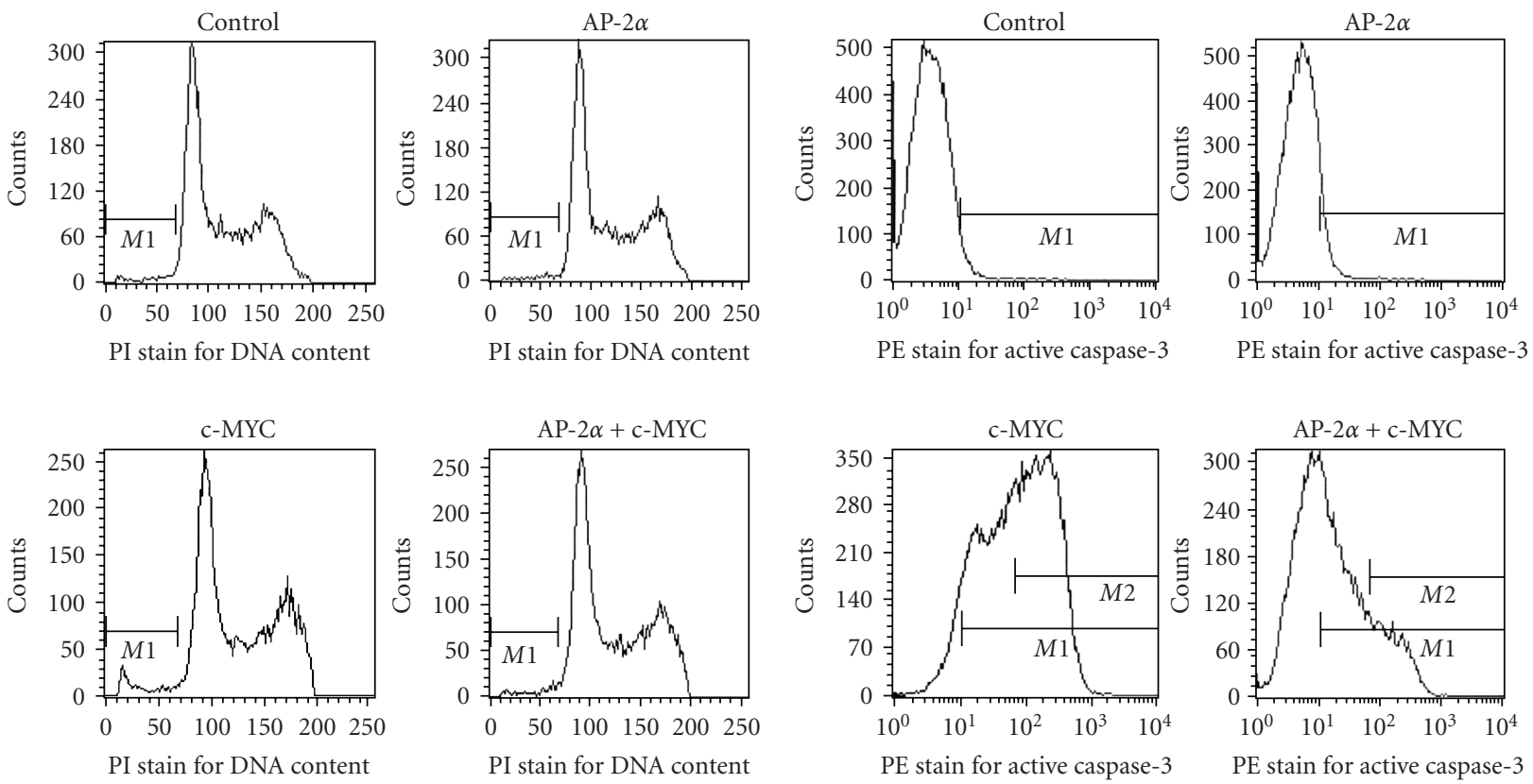

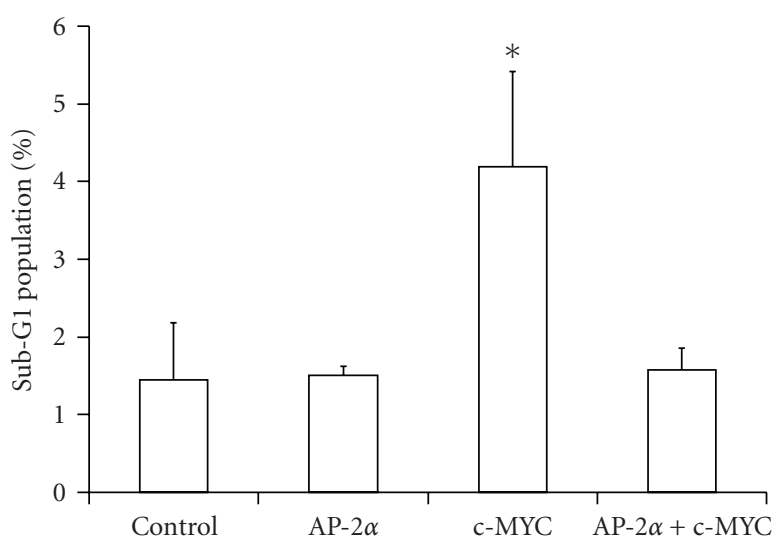

(a)

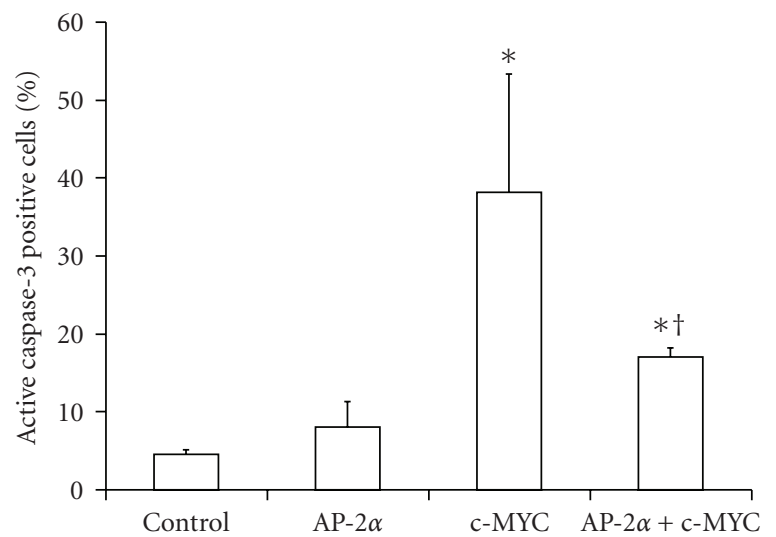

(b)

FIgure 4: Wild type AP-2 $\alpha$ attenuated apoptosis induced by c-MYC in HaCaT cells. HaCaT cells were infected with Ad-Bgl II $100 \mathrm{MOI}$ (Control), 50 MOI Ad-Bgl II + 50 MOI Ad-AP-2 (AP-2 $\alpha$ ), 50 MOI Ad-Bgl II + 50 MOI Ad-c-MYC (c-MYC), or 50 MOI Ad-AP-2 + 50 MOI Ad-c-MYC (AP-2 $\alpha+$ c-MYC). Propidium iodide (PI) staining for sub-G1 and phycoerythrin (PE)-conjugated anti-caspase-3 antibody staining for active caspase-3 were performed as indicated in the Materials and Methods section. (a) AP-2 $\alpha$ decreased the sub-G1 population induced by c-MYC. Upper panels: representative flow cytometry plots of PI-sub-G1 DNA content (M1) in the variously treated cells. Lower panel: quantitative determination of sub-G1 DNA content. Error bars represent standard deviations, $n \geq 4$. ${ }^{*} P<.01$ compared to control, AP- $2 \alpha$, and AP- $2 \alpha+$ c-MYC groups. (b) AP- $2 \alpha$ decreased the percentage of cells positive for active caspase- 3 induced by c-MYC. Upper panels: representative flow cytometry plots of measurement of PE-active caspase-3. Lower panel: quantitative determination of active caspase-3. Error bars represent standard deviations, $n \geq 4 .{ }^{*} P<.01$ compared to control, ${ }^{\dagger} P<.05$ compared to control and c-MYC group.

them, c-MYC has attracted a great deal of attention because of its broad relationship to human oncogenesis. c-MYC is overexpressed in many cancer types while at the same time, it also exhibits the ability to induce apoptosis $[6,9]$. The mechanisms through which c-MYC mediates its diverse effects are unknown. Besides functioning as a traditional transcription factor binding to DNA elements, c-MYC has been also found to directly interact with a diverse array of other proteins including p107, BIN1, TRRAP, MM-1, AMY1, Pam, $\alpha$-tubulin, Max, YY1, AP-2, TFII-I, BRCA1, and Miz1 [2]. The C-terminal domain (CTD) of c-MYC interacts with Max to form heterodimers and binds to DNA elements, while the $\mathrm{N}$-terminal domain shows both transcription activation and transcription repression functions. Gaubatz et al. showed that AP- $2 \alpha$ interacted with the c-MYC CTD both directly and indirectly [16]. These authors showed that AP- $2 \alpha$ inhibited c-MYC DNA binding activity at the ornithine decarboxylase promoter either by competing with Myc/Max heterodimers for the E-box at the promoter region or by interacting with c-MYC directly within its CTD.

In the present study we found that overexpression of c-MYC in HaCaT human keratinocytes induced apoptosis 


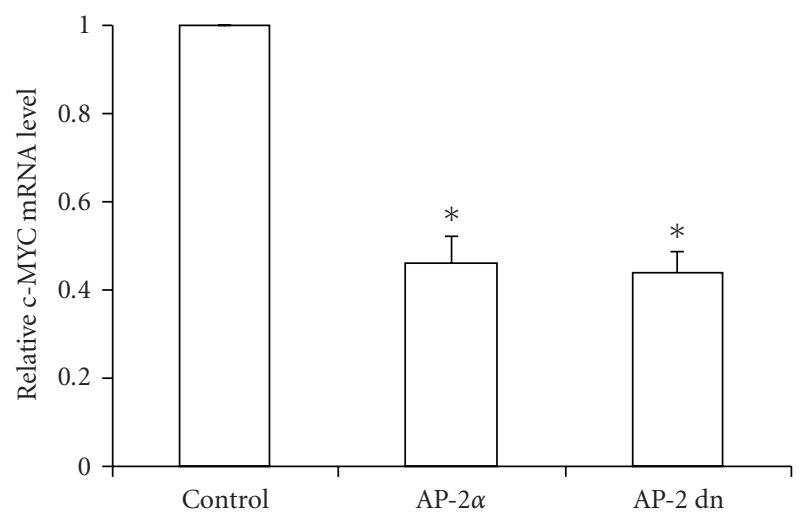

(a)

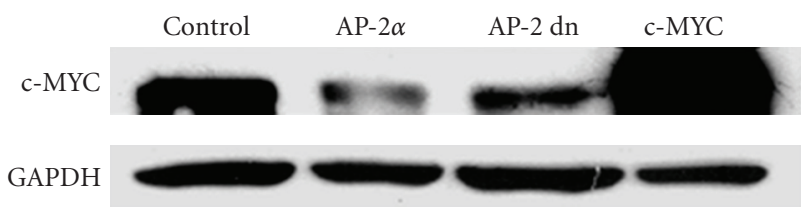

(b)

FIgURE 5: Both wild type and dominant negative AP-2 inhibit endogenous $c-m y c$ expression. HaCaT cells were infected with AdBgl II (Control), wild type AP- $2 \alpha$, dominant negative AP-2, or c-MYC adenovirus at 100 MOI. Twenty-four hours later, nuclear protein and total RNA were extracted. (a) c-MYC mRNA level decreased to about $50 \%$ compared to control group after AP2 infection ( ${ }^{*} P<.05$ versus BglII control, $n=3$ ). (b) c-MYC protein level decreased after AP-2 infection, The fourth lane is a positive control sample from Ad-c-MYC infected HaCaT cells (representative blot of three independent experiments).

and significantly decreased clonogenic survival, and that this was associated with significantly increased ROS levels. Since AP- $2 \alpha$ has been shown to inhibit c-MYC activity possibly through a protein-protein interaction [16], we hypothesized that AP- $2 \alpha$ attenuated apoptosis induced by c-MYC through this mechanism; and since the protein-protein interaction is via the $\mathrm{C}$-terminus of $\mathrm{AP}-2 \alpha$, we also hypothesized that the transactivating domain of AP- $2 \alpha$ was not required for such inhibition. Our current findings, that co-overexpression of AP- $2 \alpha$ resulted in decreased ROS levels, increased survival, and decreased apoptosis induced by c-MYC provide support for these hypotheses. More importantly, our study demonstrates for the first time that AP- $2 \alpha$ directly bound to the $c-m y c 5^{\prime}$ flanking regulatory region in vivo and blocked the expression of c-MYC mRNA (Figures 5 and 6). There are 11 putative AP-2 binding sites located within the $2 \mathrm{~kb}$ $5^{\prime}$ flanking region of the $c-m y c$ gene. We chose two clusters of these sites close to the transcription start site for ChIP analysis. We found that when AP-2 (either wild type or dominant negative) was overexpressed, c-MYC expression was inhibited and at the same time, the binding of AP-2 to those two clusters increased approximately by 6 folds. Analysis of the $c-m y c$ promoter sequence also revealed other transcription factor binding sites overlapping the AP-2 sites. These transcription factors include Sp1, NF-1, GATA-1, and GR. Since Sp1 mediated the activation of $c-m y c$ [26] as well as many other genes, the overlapping AP-2 binding sites suggest a mechanism for c-MYC inhibition similar to that by which AP- $2 \alpha$ inhibits the expression of MnSOD by competing with Sp1 on the MnSOD promoter [21].

Both c-MYC and AP- $2 \alpha$ proteins have paradoxical effects in carcinogenesis and apoptosis. In our study we found that at $50 \mathrm{MOI}$, Ad-c-MYC could cause a massive apoptosis in $\mathrm{HaCaT}$ cells. $\mathrm{HaCaT}$ cells express mutant p53 [27, 28], thus we believe that the apoptosis induced by c-MYC in our study was p53 independent. AP- $2 \alpha$ has been shown to directly interact with p53 [29] and may thus help regain the DNA binding and transcriptional activity of mutant p53. The inhibition of the apoptosis executed by AP- $2 \alpha$ in our study seems to occur through a direct block to c-MYC protein and was p53 independent.

In summary, as a negative regulator for $\mathrm{c}-\mathrm{MYC}, \mathrm{AP}-2 \alpha$ inhibits c-MYC at two different levels. First, AP- $2 \alpha$ directly inhibits $c-m y c$ gene expression through binding to its $5^{\prime}$ regulatory region. Second, AP- $2 \alpha$ has the ability to attenuate the apoptosis induced by c-MYC through protein-protein interaction and this effect did not require the transcriptional activity of AP-2.

\section{Materials and Methods}

4.1. Adenovirus Construction. The AP-2dn cDNA (a mutant form of AP- $2 \alpha$ with a deletion of the transactivation domain encompassing amino acids 31-117) was provided by Dr. Lubomir Turek and was subcloned into pcDNA3 [30]. The coding sequences were then cloned into a shuttle vector provided by Gene Transfer Vector Core, the University of Iowa. The E1A replication deficient adenovirus was constructed with the established protocol [31]. The wild type AP- $2 \alpha[30]$ adenovirus was constructed with same method and has been previously described [25]. The Ad-c-MYC [32] was amplified and maintained by the Gene Transfer Vector Core at The University of Iowa.

4.2. Cell Culture. HaCaT cells [33] were cultured in Dulbecco's Modified Eagle Medium (DMEM) supplemented with $10 \% \mathrm{FBS}$ at $37^{\circ} \mathrm{C}$ in a humidified atmosphere of $5 \% \mathrm{CO}_{2}$ and $95 \%$ air to reach $70-90 \%$ confluence prior to adenovirus infections. For clonogenic survival analyses, cells were infected with Ad-Bgl II, Ad-AP-2 $\alpha$, Ad-c-MYC, or Ad-AP-2dn as indicated. Twenty-four hours later, cells were trypsinized and counted. One hundred cells from each group were seeded into each well of six-well plates. After 14 days under normal growth condition, the resulting colonies were stained with $0.5 \%$ crystal violet in $70 \%$ ethanol, and colonies with $\geq 50$ cells were counted under dissection microscope. For growth curve, cells in sample wells were counted every other day.

4.3. Intracellular Peroxide Measurement. The intracellular peroxide concentration was measured with $2^{\prime}, 7^{\prime}$ dichlorodihydrofluorescein diacetate (DCFH-DA) as previously described [34]. Briefly, cells were washed with $1 \times$ PBS, and $3 \mathrm{~mL}$ of $10 \mu \mathrm{M}$ DCFH-DA $(20 \mu \mathrm{L}$ of $20 \mathrm{mM}$ stock in 


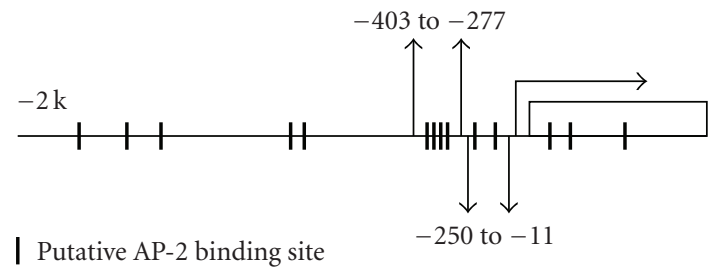

(a)
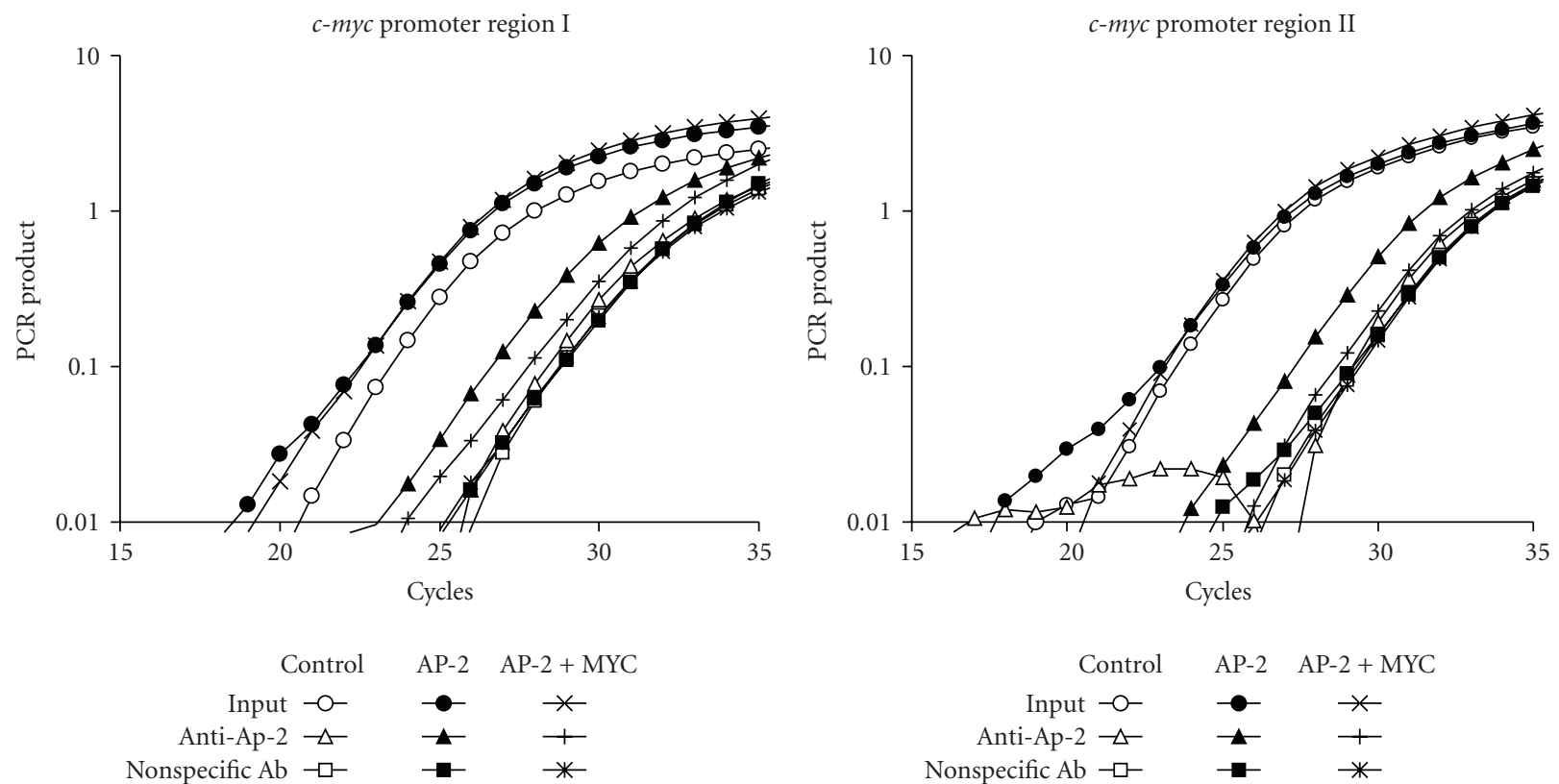

$\begin{array}{rcc}\text { Control } & \text { AP-2 } & \text { AP-2 }+ \text { MYC } \\ \text { Input }-\circ- & - & - \\ \text { Anti-Ap-2 }-\triangle & - & + \\ \text { Nonspecific Ab } \neg- & - & -\end{array}$

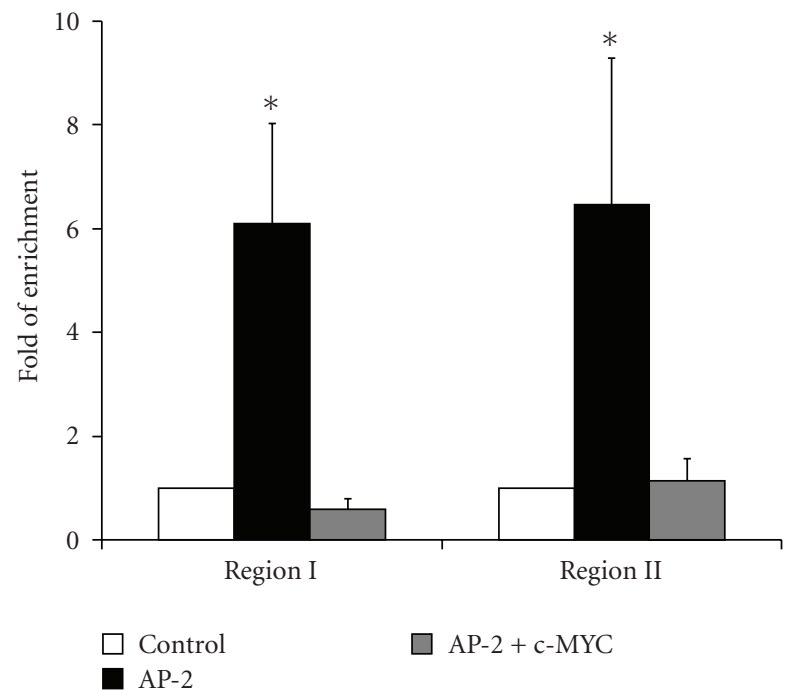

(b)

FIGURE 6: AP-2 $\alpha$ protein bound to $c-m y c 5^{\prime}$ flank regulatory region. (a) Diagram of the location of AP-2 putative binding sites in $c$-myc $5^{\prime}$ flank regulatory region (short columns). The gray short arrow heads represent the primers for ChIP assay. (b) Overexpression of AP- $2 \alpha$ caused enrichment of two promoter regions DNA with anti-AP-2 antibody in ChIP assay. Region I ( -403 to -277$)$ and Region II ( -250 to -11$)$ were both enriched about 6 folds. Cooverexpression of c-MYC (50 MOI) decreased AP-2 binding to $c$-myc promoter back to basal level. Upper panels are representative amplification curves of the real time PCR for ChIP assay; lower panel is a plot of the quantification of the data calculated with $\Delta \Delta \mathrm{Ct}$. Error bars stand for standard deviation (SD), $n=3$. ${ }^{*} P<.05$ compared to control. 
$40 \mathrm{~mL}$ PBS, Molecular Probes) was added to each plate and incubated at $37^{\circ} \mathrm{C}$ for 30 minutes. Cells were washed with PBS, and then lysed with $800 \mu \mathrm{L}$ of $0.5 \%$ NP-40. Cell lysates were centrifuged at $10000 \times \mathrm{g}$ at $4^{\circ} \mathrm{C}$ for 3 minutes. $180 \mu \mathrm{L}$ of lysate from each sample was loaded into 96-well NUNC black bottom plate and read in a SPECTRAFLUOR Plus microplate reader (TECAN, Austria) with excitation wavelength of $485 \mathrm{~nm}$ and emission wavelength of $530 \mathrm{~nm}$. The protein concentration in the remaining lysate was determined and DCF fluorescence intensity per mg protein was calculated. In separate control groups, an oxidized (DCF-DA) probe was used the same way to control for the uptake and efflux of the probe.

4.4. Apoptosis Assay. Two methods were applied to analyze the fraction of apoptotic cells. For propidium iodide (PI) staining, $1 \times 10^{6}$ cells from each group were fixed with $70 \%$ ethanol at $4^{\circ} \mathrm{C}$ for one hour. Cells were then washed two times with $1 \times \mathrm{PBS}$ and then stained with $50 \mu \mathrm{g} / \mathrm{mL}$ PI at the presence of $0.25 \mathrm{mg} / \mathrm{mL}$ RNase A at $4^{\circ} \mathrm{C}$ for 30 minutes at dark. The Active Caspase-3 Apoptosis Kit (BD Pharmingen, catalog number 550914) was used for the active caspase-3 analysis according to the manufacturer's instructions. The number of cells in the sub-G1 population was obtained by counting 10000 cells for each sample by flow cytometry (Becton Dickinson FACscan). For active capase-3, 30000 cells were counted for each sample.

4.5. Nuclear Protein Extraction. After treatment, cells were harvested by trypsinization and collected by centrifugation in $15 \mathrm{~mL}$ tubes. Cell pellets from individual cultures were rinsed twice in ice-cold PBS and resuspended in $0.5 \mathrm{~mL}$ of ice-cold hypotonic buffer [20 mM HEPES- $\mathrm{HCl}$ (pH 7.6), $1 \mathrm{mM}$ ethylenediamine tetraacetic acid (EDTA), $10 \mathrm{mM} \mathrm{NaCl}, 1 \mathrm{mM}$ dithiothreitol, and $0.5 \%$ Nonidet P40] containing protease inhibitors. The cell suspension was transferred to a $1.5 \mathrm{~mL}$ microfuge tube, incubated on ice for 20 minutes, vortexed for 10 seconds, and centrifuged for 60 seconds at $6000 \mathrm{~g}$. The supernatant (cytoplasmic extract) was transferred to a new tube. The pelleted nuclei were washed twice with $1 \mathrm{~mL}$ of ice-cold hypotonic buffer and resuspended in $0.1 \mathrm{~mL}$ of extraction buffer $(20 \mathrm{mM}$ HEPES$\mathrm{HCl} \mathrm{pH}$ 7.6, $1 \mathrm{mM}$ EDTA, $430 \mathrm{mM} \mathrm{NaCl}, 1 \mathrm{mM}$ dithiothreitol, and $0.5 \%$ Nonidet P-40) containing the protease inhibitors. After 20 minutes on ice with occasional shaking, the suspension was centrifuged for 15 minutes at $16000 \mathrm{~g}$ at $4^{\circ} \mathrm{C}$, and the supernatant (nuclear extract) was transferred to a new tube. After determination of protein concentration, aliquots of each extract were stored at $-80^{\circ} \mathrm{C}$ until use.

4.6. Western Blot Assay. Proteins were boiled with same volume of $2 \times$ sample buffer $(125 \mathrm{mM}$ Tris $\mathrm{pH} 6.8,4 \%$ SDS, $10 \%$ glycerol, $0.006 \%$ bromophenol blue, and $1.8 \%$ beta-mercaptoethanol) and were separated in a $12 \%$ SDSPAGE gel, then transferred to nitrocellulose membranes at $100 \mathrm{~V}, 4^{\circ} \mathrm{C}$ for 1 hour. The membrane was blocked with $5 \%$ nonfat milk at room temperature for 1 hour and incubated with either AP-2 $\alpha$ antibody 3B5 (Santa Cruz Biotechnology, Santa Cruz, CA) or MYC antibody (obtained from University of Iowa Hybridoma Core) $1: 1000$ at room temperature for 1 hour. The membrane was washed with $1 \times$ TBST (10 mM Tris- $\mathrm{HCl}, \mathrm{pH} 7.5,150 \mathrm{mM} \mathrm{NaCl}, 0.05 \%$ Tween20) buffer 5 times for 5 minutes each and then incubated with the second antibody (goat anti-mouse, HRP labeled, 1 : 10000 ) at room temperate for 45 minutes. The membrane was washed again with $1 \times$ TBST buffer 5 times for 5 minutes each time and the proteins were visualized by adding ECL buffer to the membrane and exposing to X-ray film.

4.7. RNA Extraction, Reverse Transcription, and Quantitative PCR for Measuring c-MYC mRNA. RNeasy Kits (Qiagen) were used to extract total RNA following manufacturer's protocol. High Capacity cDNA Archive kits from ABI (Foster City, CA) were used to prepare cDNA following manufacturer's protocols. Briefly, $2 \mu \mathrm{g}$ of total RNA was reverse transcribed to cDNA in a $100 \mu \mathrm{L}$ reaction at $37^{\circ} \mathrm{C}$ for 2 hours. Every $1 \mu \mathrm{L}$ RT reaction is equivalent to cDNA resulting from 20 ng RNA. Steady state c-MYC mRNA levels were measured using the SYBR Green method (ABI, Valencia, CA) according to manufacturer's instructions. The primers for $\mathrm{c}-\mathrm{MYC}$ were forward: $5^{\prime}$-CCA CAC ATC AGC ACA ACT ACG CT and reverse: $5^{\prime}$-GCA TTT TCG GTT GTT GCT GAT C. The primers for $18 \mathrm{~S}$ were forward: $5^{\prime}$-ACC GCG GTT CTA TTT TGT TG and reverse: $5^{\prime}$-CCC TCT TAA TCA TGG CCT CA. The relative c-MYC mRNA levels were calculated by normalizing to 18 seconds and comparing the $\Delta \Delta$ Ct between control group and AP-2 overexpressed group according to manufacturer's instructions.

\subsection{In Vivo Quantitative Chromatin Immunoprecipitation} (qChIP) Assay. Twenty million $\mathrm{HaCaT}$ cells from each group were cross-linked for 15 minutes at $37^{\circ} \mathrm{C}$ using $1 \%$ formaldehyde. Cells were washed twice with $1 \times$ PBS. The cells were then pelleted by centrifugation at $500 \mathrm{~g}$ for 10 minutes and resuspended in $500 \mathrm{~mL}$ sonication buffer (50 mM Tris-Cl pH 8.1, $10 \mathrm{mM}$ EDTA, and 1\% SDS + protease inhibitors) and sonicated twice for 10 seconds to achieve an optimal fragment length between 300-600 bp. Cross-linked DNA/proteins were then diluted 1:10 using IP dilution buffer (0.01\% SDS, $1.1 \%$ Trition-X 100, $1.2 \mathrm{mM}$ EDTA, $16.7 \mathrm{mM}$ Tris-Cl, pH 8.1, $167 \mathrm{mM} \mathrm{NaCl}$ ) plus protease inhibitors. Samples were then precleared using $70 \mu \mathrm{L}$ of Protein G agarose (Upstate Biotech, Charlottesville, VA) for 1 hour at $4^{\circ} \mathrm{C}$. Approximately 1/10th of the sample was removed as input control, while the remainder was immunoprecipitated with $10 \mu \mathrm{g}$ of anti-AP-2 $\alpha$ (Upstate Biotech, Charlottesville, VA) or control mouse IgG overnight at $4{ }^{\circ} \mathrm{C}$ with agitation. Chromatin/antibody complexes were then collected using Protein G agarose followed by washing and elution according to the manufacturer's procedure. DNA was purified from input chromatin and immunoprecipitation elutions by reversing cross-links using $200 \mathrm{mM} \mathrm{NaCl}$ at $65^{\circ} \mathrm{C}$ for 4 hours followed by the Qiagen DNeasy Kit (Qiagen, Valencia, CA) according to manufacturer's protocol. Purified 
DNA was then quantified by using a Biophotometer (Eppendorf, Hamburg, Germany). Five ng of DNA from input, antiAP-2 pull down, and nonspecific antibody pull down were analyzed with real time PCR from each of the following groups: total input, anti-AP-2 IP, and nonspecific antibody IP.

The primer sequences for amplifying the $c$-myc promoter region I were forward: $5^{\prime}$-TCC ATG CGG CTC TCT TAC TCT G and reverse: $5^{\prime}$-GCT TTG GGA ACC CGG G. For the second region they were forward: $5^{\prime}$-ATC CTC TCT CGC TAA TCT CCG C and reverse: $5^{\prime}$-AAT TAC TAC AGC GAG TTA GAT AAA GC. We used a previously known AP-2 binding site in ICAM-1 promoter [22] as a positive control. The primer sequences for the ICAM-1 promoter region: forward: 5'-AGG ATG ACC CTC TCG GCC and reverse: 5' TGC TGC AGT TAT TTC CGG ACT. The fold-enrichments were calculated by comparing the $\Delta \Delta \mathrm{Ct}$ [35] between control group and AP-2 overexpressed group. $\Delta \mathrm{Ct}=\mathrm{Ct}$ (Anti-AP-2 pull down $)-\mathrm{Ct}$ (Nonspecific Ab pull down). $\Delta \Delta \mathrm{Ct}=\Delta \mathrm{Ct}$ (AP-2 overexpressed group) $-\Delta \mathrm{Ct}$ (Control group). Fold of enrichment $=2^{-\Delta \Delta \mathrm{Ct}}$.

4.9. Statistical Analysis. A single factor ANOVA, followed by Student's $t$-test was used to compare statistical differences between means. Statistical significance was set at the 0.05 level.

\section{Acknowledgment}

This work was supported by NIH Grants R01-CA073612 (F.E.D.), R01-CA115438 (F.E.D.), R01-CA111365 (P.C.G.), R01-AG0227388 (A.J.K.), and P30-CA086862.

\section{References}

[1] C. Murre, P. S. McCaw, and D. Baltimore, "A new DNA binding and dimerization motif in immunoglobulin enhancer binding, daughterless, MyoD, and myc proteins," Cell, vol. 56, no. 5, pp. 777-783, 1989.

[2] D. Sakamuro and G. C. Prendergast, "New Myc-interacting proteins: a second Myc network emerges," Oncogene, vol. 18, no. 19, pp. 2942-2954, 1999.

[3] K. D. Hanson, M. Shichiri, M. R. Follansbee, and J. M. Sedivy, "Effects of c-myc expression on cell cycle progression," Molecular and Cellular Biology, vol. 14, no. 9, pp. 5748-5755, 1994.

[4] C. A. Spencer and M. Groudine, "Control of c-myc regulation in normal and neoplastic cells," Advances in Cancer Research, vol. 56, pp. 1-48, 1991.

[5] S. Aulmann, N. Adler, J. Rom, B. Helmchen, P. Schirmacher, and H. P. Sinn, "c-myc amplifications in primary breast carcinomas and their local recurrences," Journal of Clinical Pathology, vol. 59, no. 4, pp. 424-428, 2006.

[6] S. Pelengaris, M. Khan, and G. Evan, "c-MYC: more than just a matter of life and death," Nature Reviews Cancer, vol. 2, no. 10, pp. 764-776, 2002.

[7] H.-J. Chung and D. Levens, "c-myc expression: keep the noise down!," Molecules and Cells, vol. 20, no. 2, pp. 157-166, 2005.

[8] D. S. Askew, J. N. Ihle, and J. L. Cleveland, "Activation of apoptosis associated with enforced Myc expression in myeloid progenitor cells is dominant to the suppression of apoptosis by interleukin-3 or erythropoietin," Blood, vol. 82, no. 7, pp. 2079-2087, 1993.

[9] G. I. Evan, A. H. Wyllie, C. S. Gilbert, et al., "Induction of apoptosis in fibroblasts by c-myc protein," Cell, vol. 69, no. 1, pp. 119-128, 1992.

[10] P. Gallant, Y. Shiio, P. F. Cheng, S. M. Parkhurst, and R. N. Eisenman, "Myc and Max homologs in Drosophila," Science, vol. 274, no. 5292, pp. 1523-1527, 1996.

[11] C. de La Cova, M. Abril, P. Bellosta, P. Gallant, and L. A. Johnston, "Drosophila myc regulates organ size by inducing cell competition," Cell, vol. 117, no. 1, pp. 107-116, 2004.

[12] A.-O. Hueber, M. Zörnig, D. Lyon, T. Suda, S. Nagata, and G. I. Evan, "Requirement for the CD95 receptor-ligand pathway in c-Myc-induced apoptosis," Science, vol. 278, no. 5341, pp. 1305-1309, 1997.

[13] O. Vafa, M. Wade, S. Kern, et al., "c-Myc can induce DNA damage, increase reactive oxygen species, and mitigate p53 function: a mechanism for oncogene-induced genetic instability," Molecular Cell, vol. 9, no. 5, pp. 1031-1044, 2002.

[14] D. Sakamuro, V. Eviner, K. J. Elliott, L. Showe, E. White, and G. C. Prendergast, "c-Myc induces apoptosis in epithelial cells by both p53-dependent and p53-independent mechanisms," Oncogene, vol. 11, no. 11, pp. 2411-2418, 1995.

[15] E. M. Blackwood, B. Luscher, L. Kretzner, and R. N. Eisenman, "The Myc:Max protein complex and cell growth regulation," Cold Spring Harbor Symposia on Quantitative Biology, vol. 56, pp. 109-117, 1991.

[16] S. Gaubatz, A. Imhof, R. Dosch, et al., "Transcriptional activation by Myc is under negative control by the transcription factor AP-2," The EMBO Journal, vol. 14, no. 7, pp. 1508-1519, 1995.

[17] K. Hilger-Eversheim, M. Moser, H. Schorle, and R. Buettner, "Regulatory roles of AP-2 transcription factors in vertebrate development, apoptosis and cell-cycle control," Gene, vol. 260, no. 1-2, pp. 1-12, 2000.

[18] J. Pellikainen, V. Kataja, K. Ropponen, et al., "Reduced nuclear expression of transcription factor AP-2 associates with aggressive breast cancer," Clinical Cancer Research, vol. 8, no. 11, pp. 3487-3495, 2002.

[19] J. M. W. Gee, J. F. R. Robertson, I. O. Ellis, R. I. Nicholson, and H. C. Hurst, "Immunohistochemical analysis reveals a tumour suppressor-like role for the transcription factor AP2 in invasive breast cancer," Journal of Pathology, vol. 189, no. 4, pp. 514-520, 1999.

[20] C.-H. Zhu and F. E. Domann, "Dominant negative interference of transcription factor AP-2 causes inhibition of ErbB3 expression and suppresses malignant cell growth," Breast Cancer Research and Treatment, vol. 71, no. 1, pp. 47-57, 2002.

[21] C. Zhu, Y. Huang, C. J. Weydert, L. W. Oberley, and F. E. Domann, "Constitutive activation of transcription factor AP-2 is associated with decreased MnSOD expression in transformed human lung fibroblasts," Antioxidants and Redox Signaling, vol. 3, no. 3, pp. 387-395, 2001.

[22] S. Grether-Beck, S. Olaizola-Horn, H. Schmitt, et al., "Activation of transcription factor AP-2 mediates UVA radiationand singlet oxygen-induced expression of the human intercellular adhesion molecule 1 gene," Proceedings of the National Academy of Sciences of the United States of America, vol. 93, no. 25, pp. 14586-14591, 1996.

[23] K. Ariizumi, P. R. Bergstresser, and A. Takashima, "Wavelength-specific induction of immediate early genes by ultraviolet radiation," Journal of Dermatological Science, vol. 12, no. 2, pp. 147-155, 1996. 
[24] A. Drobyshevsky, A. M. Robinson, M. Derrick, et al., "Sensory deficits and olfactory system injury detected by novel application of MEMRI in newborn rabbit after antenatal hypoxiaischemia," NeuroImage, vol. 32, no. 3, pp. 1106-1112, 2006.

[25] H. Li, P. C. Goswami, and F. E. Domann, "AP- $2 \gamma$ induces p 21 expression, arrests cell cycle, and inhibits the tumor growth of human carcinoma cells," Neoplasia, vol. 8, no. 7, pp. 568-577, 2006.

[26] B. Majello, P. de Luca, G. Suske, and L. Lania, "Differential transcriptional regulation of $\mathrm{c}$-myc promoter through the same DNA binding sites targeted by Sp1-like proteins," Oncogene, vol. 10, no. 9, pp. 1841-1848, 1995.

[27] T. A. Lehman, R. Modali, P. Boukamp, et al., "p53 mutations in human immortalized epithelial cell lines," Carcinogenesis, vol. 14, no. 5, pp. 833-839, 1993.

[28] M. Negrini, S. Sabbioni, S. Haldar, et al., "Tumor and growth suppression of breast cancer cells by chromosome 17-associated functions," Cancer Research, vol. 54, no. 7, pp. 1818-1824, 1994.

[29] L. A. McPherson, A. V. Loktev, and R. J. Weigel, “Tumor suppressor activity of AP $2 \alpha$ mediated through a direct interaction with p53," The Journal of Biological Chemistry, vol. 277, no. 47, pp. 45028-45033, 2002.

[30] C.-H. Zhu, Y. Huang, L. W. Oberley, and F. E. Domann, "A family of AP-2 proteins down-regulate manganese superoxide dismutase expression," The Journal of Biological Chemistry, vol. 276, no. 17, pp. 14407-14413, 2001.

[31] R. D. Anderson, R. E. Haskell, H. Xia, B. J. Roessler, and B. L. Davidson, "A simple method for the rapid generation of recombinant adenovirus vectors," Gene Therapy, vol. 7, no. 12, pp. 1034-1038, 2000.

[32] H. Hermeking, C. Rago, M. Schuhmacher, et al., "Identification of CDK4 as a target of c-MYC," Proceedings of the National Academy of Sciences of the United States of America, vol. 97, no. 5, pp. 2229-2234, 2000.

[33] P. Boukamp, R. T. Petrussevska, D. Breitkreutz, J. Hornung, A. Markham, and N. E. Fusenig, "Normal keratinization in a spontaneously immortalized aneuploid human keratinocyte cell line," Journal of Cell Biology, vol. 106, no. 3, pp. 761-771, 1988.

[34] A. Keller, A. Mohamed, S. Dröse, U. Brandt, I. Fleming, and R. P. Brandes, "Analysis of dichlorodihydrofluorescein and dihydrocalcein as probes for the detection of intracellular reactive oxygen species," Free Radical Research, vol. 38, no. 12, pp. 1257-1267, 2004.

[35] L. Yu and F. E. Domann, "Rapid and direct quantitative RTPCR method to measure promoter activity," Biotechnology Progress, vol. 22, no. 5, pp. 1461-1463, 2006. 


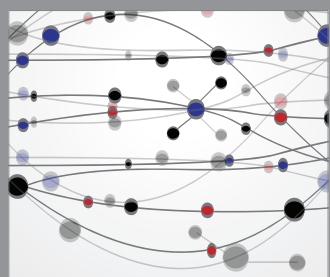

The Scientific World Journal
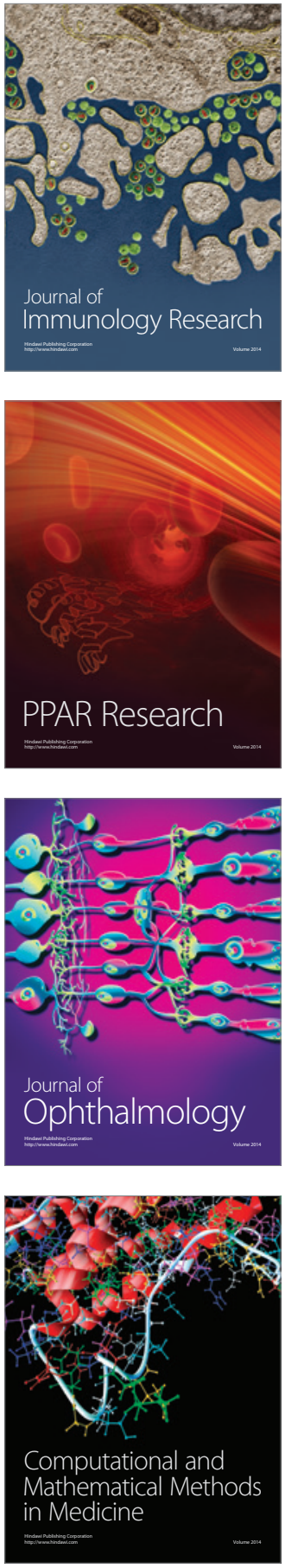

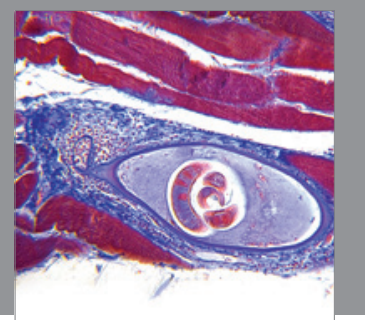

Gastroenterology

Research and Practice
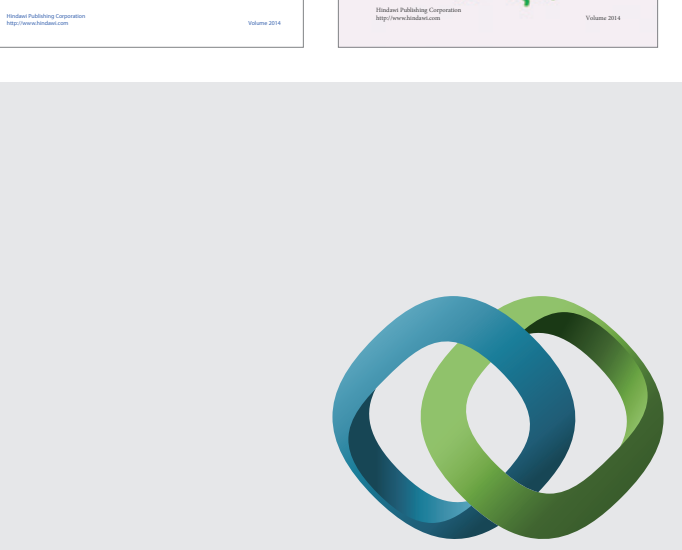

\section{Hindawi}

Submit your manuscripts at

http://www.hindawi.com
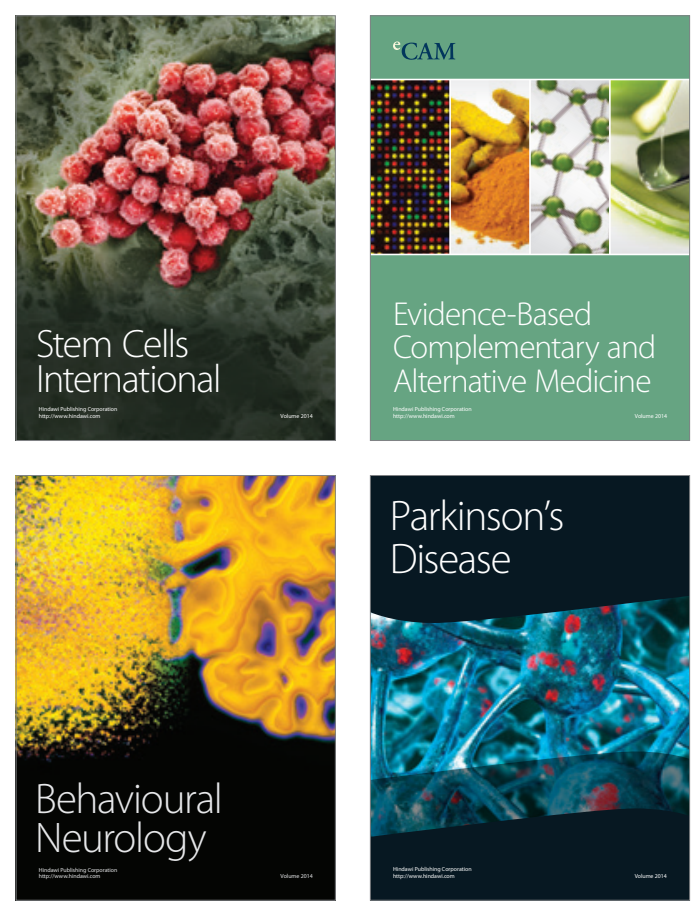

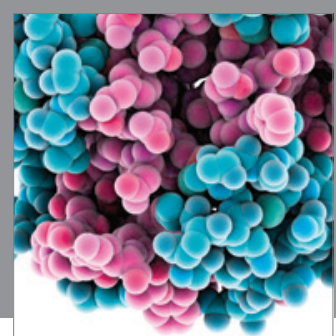

Journal of
Diabetes Research

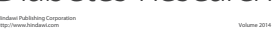

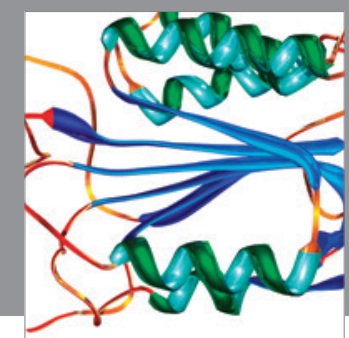

Disease Markers
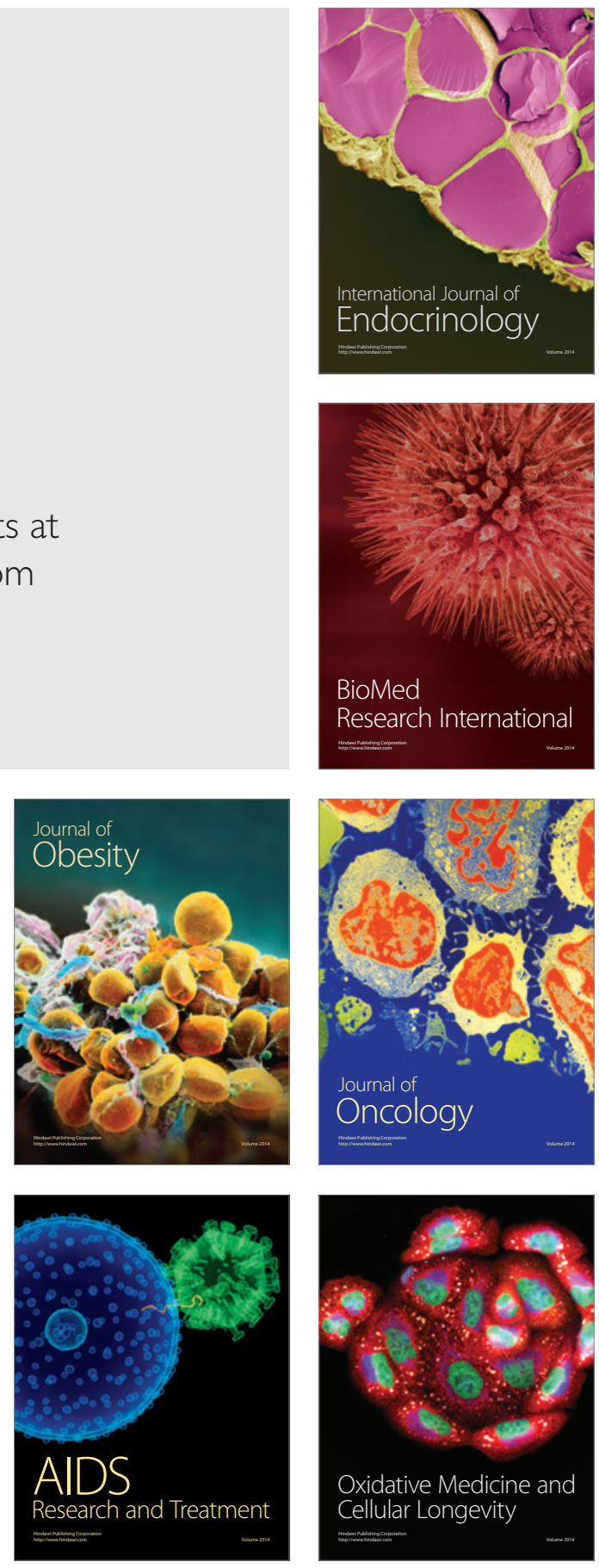